\title{
MUDANÇAS CLIMÁTICAS
}

\section{AS ÁGUAS DE MARÇO REALMENTE FECHAM O VERÃO? ESTUDO DA PRECIPITAÇÃO DIÁRIA DE MAMBORÊ-PR}

\author{
Ricardo Guicho (AUTOR PRINCIPAL) - ricardoguicho@alunos.utfpr.edu.br \\ Universidade Tecnológica Federal do Paraná. \\ Michele Suzane Saturnino de Sá (COAUTOR) - msaturninosa@ gmail.com Universidade \\ Tecnológica Federal do Paraná.
}

Paulo Agenor Alves Bueno (COAUTOR) - pauloaabueno@ gmail.com Universidade Tecnológica Federal do Paraná.

\begin{abstract}
Resumo: O estudo climático, em específico a pluviometria, tem grande importância social visto que interfere diretamente no planejamento urbano e rural. Com o intuito de conhecer o comportamento da pluviosidade do município de Mamborê-PR, realizou-se um comparativo dos dados de precipitação diários do município com a música de Tom Jobim "Águas de Março", de forma literal, para analisar se o regime forte de chuvas do Verão realmente cessa com o início do Outono, e portanto concluir se as águas de março fecham o verão. Para tal análise, os dados pluviométricos diários do município de Mamborê foram obtidos pelo Instituto das Águas do Paraná no Sistema de Informações Hidrológicas-SIH e dispostos em planilha eletrônica para posteriormente utilizá-los no programa BioEstat 5.3, onde foram realizados testes estatísticos como o de Lilliefors e Mann-Whitney. Os testes foram aplicados com o objetivo de comparação dos índices de precipitação diária entre o verão e as demais estações e uma comparação entre a última quinzena do verão com a primeira quinzena do outono em uma série histórica de 34 anos (1980-2013). Com as analises realizadas, pôde-se comprovar que o sentido literal da música não se aplica ao município de Mamborê-PR, visto que estatisticamente o final do verão e o início do outono não houve diferença significativa dos índices pluviométricos.
\end{abstract}

Palavras-chave: Mamborê, precipitação diária, sazonalidade, BioEstat.

\section{INTRODUÇÃO E OBJETIVOS}

A precipitação pluviométrica é um fator climático de grande relevância visto que, o acompanhamento da sua mensuração e análise dos dados, fornece subsídio para previsões de ocorrências de enchentes ou estiagens, aspectos que podem ocasionar problemas sérios em abastecimentos de água para as cidades ou escassez de água para a produção agrícola. Neste sentido, a análise pluviométrica é um fator de alta relevância nos estudos para o planejamento urbano (ANDRADE\&NERY, 2011). 

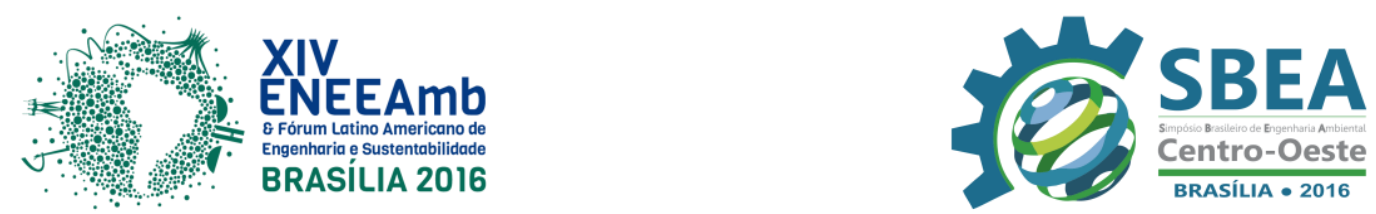

A distribuição anual de chuvas na região Sul se faz de maneira uniforme, quando comparada às outras regiões do país, de acordo com dados do CPTEC/INPE, que apontam ser a região com maior variabilidade térmica ao longo do ano.

Escrita no verão de 1972 em meio à ditadura militar que ocorria no Brasil, "Águas de Março" de Tom Jobim, teve por objetivo retratar as chuvas de Março, que marcam o final do verão e que para o compositor simbolizam o inicio de um novo ciclo com o final do regime de chuvas, de acordo com a revista Rolling Stones (2009).

Dessa forma, o presente estudo tem por objetivo analisar de forma literal se o que Tom Jobim descreve como sendo um regime forte de chuvas no final do mês de Março, realmente ocorre no município de Mamborê - PR. Tendo por base uma série histórica de trinta e quatro anos de índices diários de pluviosidade no município, examinando cientificamente, se as "águas de março" realmente fecham o verão.

\section{METODOLOGIA}

Os dados de precipitação pluviométrica diária do presente trabalho foram obtidos a partir do posto pluviométrico do Instituto das Águas do Paraná - Sistema de Informações Hidrológicas - SIH, trabalhando com uma série histórica de 34 anos, com intervalo de tempo de 1980 - 2013. O posto de coleta de dados se localiza no município de Mamborê - PR, com latitude $24^{\circ} 16^{\prime} 59^{\prime}$ ' S, longitude $52^{\circ} 31^{\prime} 00^{\prime}$ 'W e altitude de $702 \mathrm{~m}$, inserido na bacia hidrográfica do rio Mourão, que está contida na bacia do rio Ivaí.

Os dados foram preparados em planilha eletrônica para realização dos cálculos estatísticos necessários para todas as escalas de análises de frequência.

Deve-se levar em consideração que o estudo se baseia em precipitação diária e que pode ocorrer precipitação muito escassa, como pode ser de grande intensidade ou então não ocorrer nenhuma precipitação, pois o período de estudo contido em 24 horas fica estreito para obtenção de precipitação. Por este motivo considerou-se todos os valores acima de 0,1 $\mathrm{mm}$, metodologia utilizada por (SILVA et al., 2011).

Conforme análise dos dados ainda brutos para execução da metodologia estatística, foi utilizado como apoio o programa BioEstat 5.3, onde foram realizados testes estatísticos para obtenção de dados que possibilitem discussões.

Inicialmente foi aplicado o teste de normalidade de Lilliefors, utilizado em condições que possuam um número $k$ de amostras, para comparar qual o grau de concordância entre elas bem como a distribuição normal dentro dos valores de uma amostra com a distribuição teórica esperada para essa mesma amostra.

Após aplicação do teste de normalidade foram realizados testes não paramétricos para duas amostras independentes, sendo utilizando para tal aplicação o teste de MannWhitney, para obtenção de dados estatísticos.

Os testes foram aplicados com objetivo de comparação dos índices de precipitação diária entre o verão e as demais estações do ano em uma série histórica de trinta e quatro anos, de 1980 a 2013.

A partir dos dados estatísticos obtidos com a aplicação dos testes, foi realizada uma nova comparação entre última quinzena do verão e primeira quinzena no outono. Foi considerada a seguinte separação mensal para as estações: Verão: Janeiro, Fevereiro e Março; Outono: Abril, Maio e Junho; Inverno: Julho, Agosto e Setembro; Primavera: Outubro, Novembro e Dezembro. 


\section{RESULTADOS E DISCUSSÕES}

\subsection{Análise sazonal.}

Primeiramente foi realizada a análise sazonal, utilizando o BioEstat 5.3 com o método de Lilliefors (para $\mathrm{k}$ amostras), onde não apresentou distribuição normal e portanto fez-se necessário a utilização de um teste não-paramétrico.

\section{a.Verão - outono.}

De acordo com esta informação pode-se realizar o método estatístico de MannWhitney para a comparação de duas amostras independentes, ou seja, neste caso verão e outono, onde pode-se observar na Tabela 1 que o p (bilateral) apresentou valor igual a 0,0012.

Tabela 1 - Análise comparativa do verão e outono.

\begin{tabular}{|c|c|c|}
\hline Resultado & Verão & Outono \\
\hline Tamanho da amostra & 102 & 102 \\
\hline Soma dos Postos (Ri) & 11822 & 9088 \\
\hline Mediana & 167.6 & 124.85 \\
\hline U & 3835 & \\
\hline Z(U) & 3.2425 & \\
\hline p-valor (unilateral) & 0.0006 & \\
\hline p-valor (bilateral) & 0.0012 & \\
\hline
\end{tabular}

De acordo com este resultado pode-se verificarque estatisticamente o verão possui diferença de pluviosidade diária significativa quando comparado ao outono (Figura 1). Este resultado já era esperado, visto que segundo o Sistema Meteorológico do Paraná (SIMEPAR) o outono no Paraná, que é a estação subsequente ao verão, tem característica de redução no volume de chuvas.

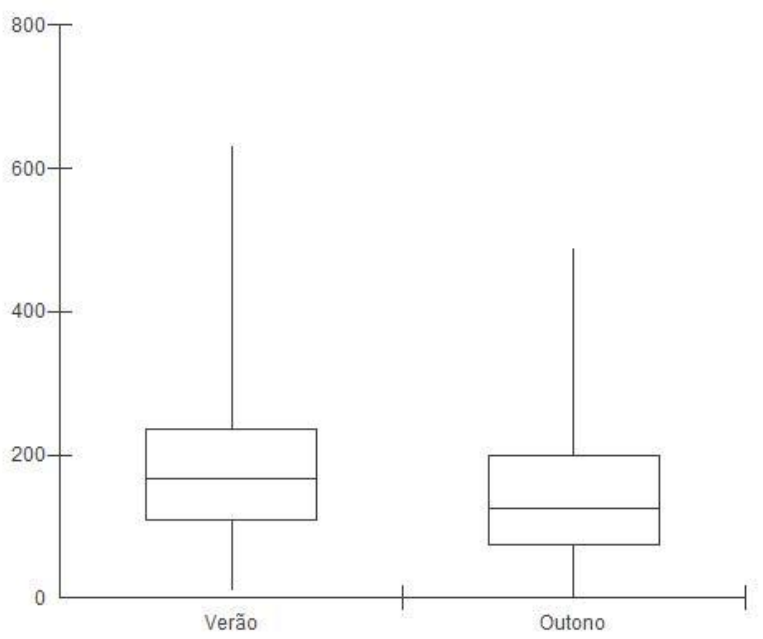

Figura 1 - Gráfico box-plot de comparação entre verão e outono. 

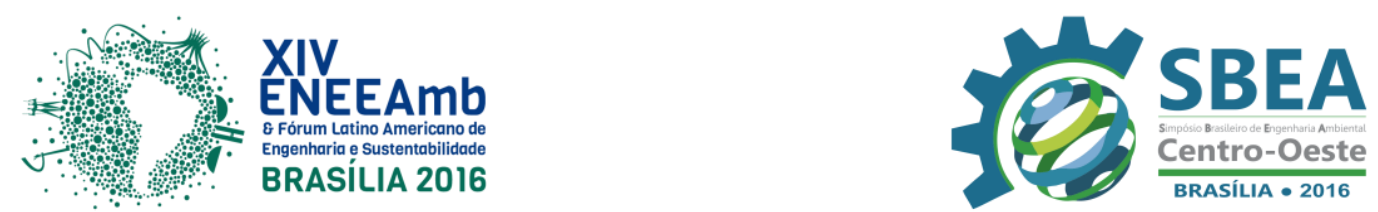

Na Tabela 2 pode-se observar a diferença quantitativa entre o verão e o outono, sendo o verão com maior índice pluviométrico, isso pode ser observado tanto em comparação dos índices, mínimo, máximo, mediana e de acordo com a média aritmética exposta das duas estações.

Tabela 2- Análise estatística do verão e outono.

\begin{tabular}{|c|c|c|}
\hline & Verão & Outono \\
\hline Tamanho da amostra & 102 & 102 \\
\hline Mínimo & 11 & 0 \\
\hline Máximo & 629.4 & 487.6 \\
\hline Amplitude Total & 618.4 & 487.6 \\
\hline Mediana & 167.6 & 124.85 \\
\hline Média Aritmética & 184.4049 & 147.9 \\
\hline Variância & 9896.3979 & 11664.8897 \\
\hline
\end{tabular}

\section{b. Verão - primavera.}

A comparação do verão com a primavera apresenta resultado diferente do que o exposto com o outono. Pode-se observar que o p(bilateral) apresentou valor de 0,5066, ou seja, não apresentou diferença estatisticamente significativa, como apresenta a Tabela 3.

Tabela 3- Análise comparativa do verão e outono.

\begin{tabular}{|c|c|c|}
\hline Resultado & Verão & Primavera \\
\hline Tamanho da amostra & 102 & 102 \\
\hline Soma dos Postos (Ri) & 10175 & 10735 \\
\hline Mediana & 167.6 & 172.15 \\
\hline U & 4922 & \\
\hline Z(U) & 0.6642 & \\
\hline p-valor (unilateral) & 0.2533 & \\
\hline p-valor (bilateral) & 0.5066 & \\
\hline
\end{tabular}

Esta análise comparativa possui uma dessemelhança com o confronto das demais estações, visto que para a séria histórica de Mamborê, a primavera possui índices pluviométricos mais altos que os do verão. Esta informação coincide com os dados apresentado pela Simepar, que refere-se a este trimestre como um aumento natural no volume das chuvas.

De acordo com o mapa do trimestre mais chuvoso, apresentado pelo Instituto Agronômico do Paraná (IAPAR), os meses inclusos são os de dezembro, janeiro e fevereiro, estão contidos dois meses da estação do verão (Janeiro e Fevereiro) e apenas um da primavera (Dezembro) e ainda assim a primavera, continua sendo a estação mais chuvosa.

Com base nessas informações gerou-se um gráfico, demonstrando a pouca significância estatística da diferença entre as médias entre o verão e a primavera (Figura 2). 


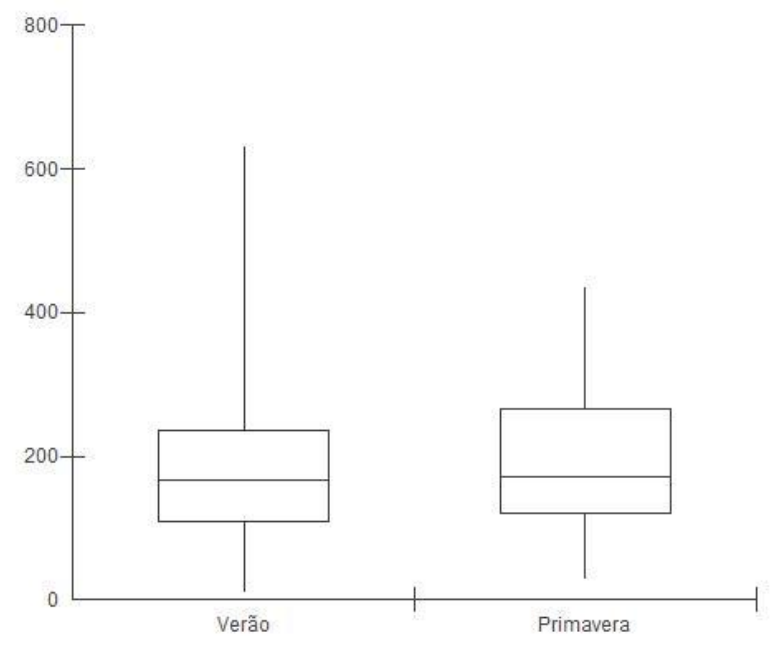

Figura 2 - Gráfico box-plot de comparação entre verão e primavera.

De acordo com a análise da estatística descritiva pode-se observar quantitativamente os dados expostos no gráfico acima. Conforme exposto na tabela 5.

Tabela 4- Análise estatística do verão e primavera.

\begin{tabular}{|c|c|c|}
\hline & Verão & Primavera \\
\hline Tamanho da amostra & 102 & 102 \\
\hline Mínimo & 11 & 29.3 \\
\hline Máximo & 629.40 & 435.30 \\
\hline Amplitude Total & 618.4 & 406 \\
\hline Mediana & 167.6 & 172.15 \\
\hline Média Aritmética & 184.4049 & 192.8824 \\
\hline Variância & 9896.3979 & 9785.5783 \\
\hline
\end{tabular}

De acordo com os dados estatísticos descritos na Tabela 4pode-se verificarque a primavera possui maiores índices de pluviosidade diária quando comparado com o verão, porém a diferença pluviométrica entre as estações não foi suficiente para que estatisticamente fosse significativa.

\section{c. Verão - inverno.}

Para a análise do verão com o inverno observa-se um resultado bastante diferente isso fica claro quando se nota o p (bilateral) apresentando um valor menor que 0,0001 , ou seja, houve diferença estatisticamente significativa. Pode-se analisar estas informações de acordo com a Tabela 5. 
Tabela 5- Análise comparativa do verão e inverno.

\begin{tabular}{|c|c|c|}
\hline Resultado & Verão & Inverno \\
\hline Tamanho da amostra & 102 & 102 \\
\hline Soma dos Postos (Ri) & 13030.5 & 7879.5 \\
\hline Mediana & 167.6 & 87.8 \\
\hline $\mathrm{U}$ & 2626.5 & \\
\hline $\mathrm{Z}(\mathrm{U})$ & 6.1091 & \\
\hline p-valor (unilateral) & $<0.0001$ & \\
\hline p-valor (bilateral) & $<0.0001$ & \\
\hline
\end{tabular}

O gráfico a seguir (Figura 3) demonstra a discrepância entre as médias do verão em comparação ao inverno com relação à pluviosidade diária. Pode-se observar o motivo de ser considerado estatisticamente significante a sua diferença.

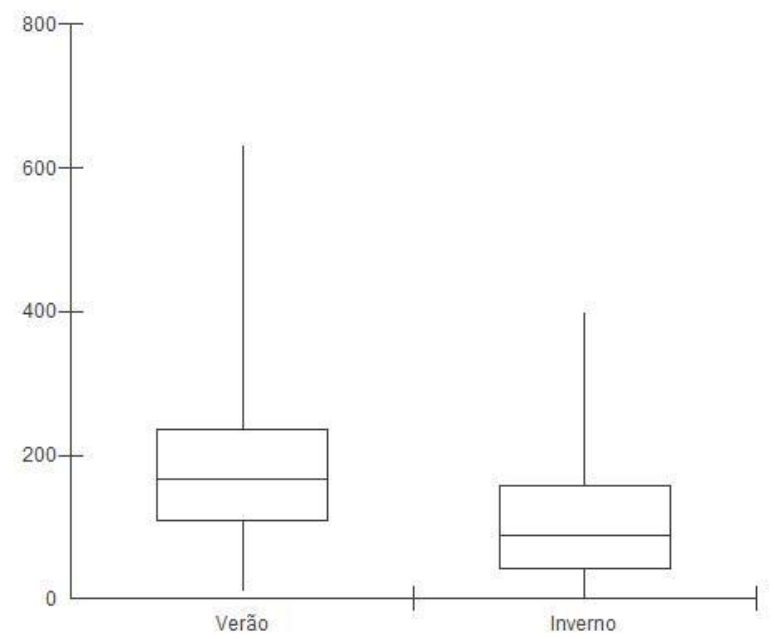

Figura 3 - Gráfico box-plot de comparação entre verão e inverno.

De acordo com a análise estatística descritiva (Tabela 6) pode-se observar quantitativamente a diferença de pluviosidade entre o verão e o inverno.

Tabela 6 - Análise estatística do verão e inverno.

\begin{tabular}{|c|c|c|}
\hline & Verão & Inverno \\
\hline Tamanho da amostra & 102.00 & 102.00 \\
\hline Mínimo & & 11 \\
\hline Máximo & 629.4 & 397.2 \\
\hline Amplitude Total & 618.4 & 396.8 \\
\hline Mediana & 167.6 & 87.8 \\
\hline Média Aritmética & 184.4049 & 106.7627 \\
\hline Variância & 9896.3979 & 7161.5263 \\
\hline
\end{tabular}



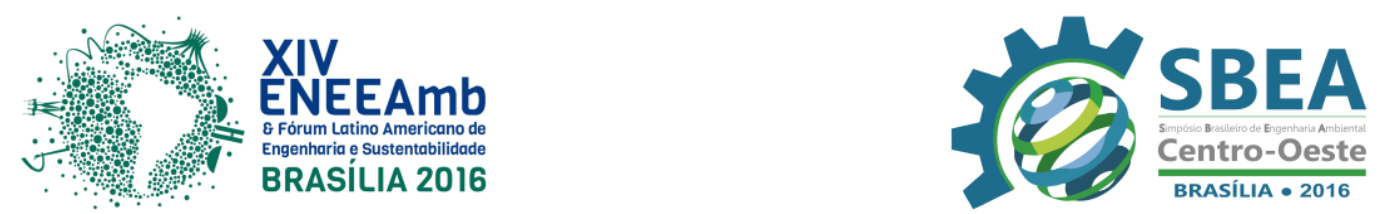

Portanto, de acordo com o exposto na Tabela 6 pode-se observar pela média aritmética que o verão possui maior pluviosidade diária que o inverno. Este dado era prenunciado visto que conforme o Centro de Previsão de Tempo e Estudos Climáticos (CPTEC) nos meses referentes ao trimestre do inverno as chuvas tendem a diminuir, tornando portanto, neste caso,estatisticamente significante essa diferença de acordo com o BioEstat 5.3.

\subsection{Análise quinzenal.}

Para avaliar se há diferença estatisticamente significativa entre o verão e o outono analisou-se a comparação da segunda quinzena de março com a primeira quinzena de abril, avaliando portanto o final do verão em comparação com o início do outono (Tabela 7).

Tabela 7 - Análise comparativa da segunda quinzena de março e a primeira quinzena de abril.

\begin{tabular}{|c|c|c|}
\hline Resultado & $2^{\text {a }}$ Quinzena de Março & $1^{\text {a }}$ Quinzena de Abril \\
\hline Tamanho da amostra & 34 & 34 \\
\hline Soma dos Postos (Ri) & 1273 & 1073 \\
\hline Mediana & 68.55 & 45 \\
\hline $\mathrm{U}$ & 478 & \\
\hline Z(U) & 1.2266 & \\
\hline p-valor (unilateral) & 0.11 & \\
\hline p-valor (bilateral) & 0.22 & \\
\hline
\end{tabular}

Com os dados analisados e os parâmetros expostos pode-se observar que o valor do p(bilateral) foi de 0,22 , ou seja, é maior que 0,05 tornando assim um índice normal da amostra, não evidenciando uma diferença que seja relevante estatisticamente entre o final do verão e o início do outono.

Este dado pode ser explicado por um fator em especial que deve ser levado em consideração, a mudança do comportamento climáticoé uma realidade incontestável, entre as suas implicações está a alteração da sistemática do regime pluviométrico, desregulando o que Neto (2005) aponta como verão austral que é o período compreendido de outubro a março em que as chuvas são abundantes e as temperaturas elevadas.

Associando, portanto, essa informação com o posicionamento da Simepar que cita, historicamente, o outono como uma estação que é caracterizada pela redução nas chuvas do verão, pode-se dizer que as mudanças climáticas podem ter interferido no regime pluviométrico, alterando o regime de sazonalidade.

\section{CONSIDERAÇÕES FINAIS}

De acordo com as análises estatísticas pôde-se ser comprovado que quando Tom Jobim cita "São as águas de março fechando o verão", em sua música "Águas de Março", levado no sentido literal, demonstrando que pelo fato do verão acabar em março, o grande fluxo hídrico da pluviometria diária característico dessa estação, diminui a partir do fim do verão e com o início do outono. Pode-se comprovar, entretanto, que tal conceito não se aplica 

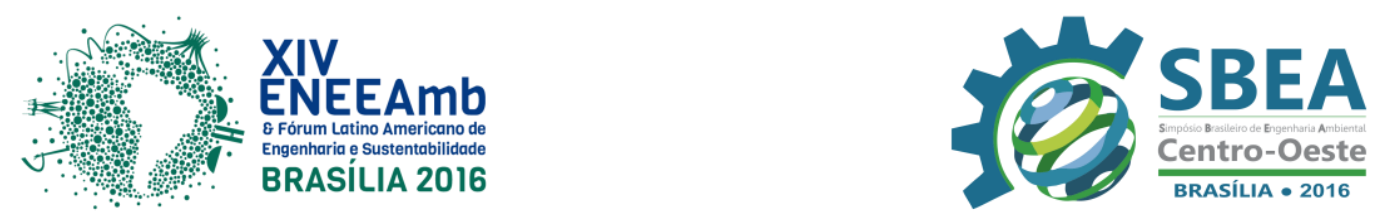

ao município de Mamborê - PR, já que estatisticamente com a análise do final do verão e o início do outono, não houve discrepância acentuada em seus índices pluviométricos diários.

A pluviometria não é fator único, dependendo de muitas variáveis climatológicas e não uniformes. Esta análise buscou averiguar, de forma literal, o possível enquadramento da música de Tom Jobim para o município de Mamborê - PR, distante $1.186 \mathrm{~km}$ do Rio de Janeiro, onde a canção foi composta em 1972, portanto passível de erros, já que existem diversos fatores intrínsecos que alteram o clima nas mais diferentes áreas além das possíveis alterações climáticas ocorridas no período.

\section{REFERÊNCIAS E CITAÇÕES}

ANDRADE, Aparecido Ribeiro de; NERY, Jonas Teixeira. Anállise Sazonal e Espacial da Precipitação Pluvial na Bacia Hidrográfica do Rio Ivaí - Paraná. Bol. geogr., Maringá, v. 29, n. 2, p. 107-121, 2011.

Centro de Previsão de Tempo e Estudos Climáticos. CPTEC/INPE. Climatologia de Precipitação e Temperatura. Disponível em: http://climanalise.cptec.inpe.br/ rclimanl/boletim/cliesp10a/chuesp.html. Acesso em 31 jan. 2015.

INSTITUTO DAS ÁGUAS DO PARANÁ. Sistema de Informações Hidrológicas. Disponível em: $\quad$ http://www.aguasparana.pr.gov.br/modules/conteudo/conteudo.php?conteudo=264. Acesso em 31/01/2015.

NETO, João Lima Sant'Anna. Decálogo da Climatologia do Sudeste Brasileiro. Revista Brasileira de Climatologia. V.1 Nº 1 . Dezembro de 2005.

ROLLING STONES. Águas de Março. Disponível em: http://rollingstone.uol.com.br/edicao/37/noticia-3940\#imagem0. Acesso em 01 fev. 2015.

SILVA, José Geraldo Ferreira da; RAMOS, Hugo Ely dos Anjos; IGREJA, Gizella Carneiro; SILVA, Alines Oliveira da; FREITAS, RozianeAtayde. Análise da Frequência da Precipitação Diária no Município de Águia Branca - ES. XVII Congresso Brasileiro de Agrometeorologia - Sesc Centro de turismo de Guarapari, Guarapari - ES.

Sistema Meteorológico do Paraná. SIMEPAR. Disponível em: http://www.simepar.br/. Acesso em 21 abr. 2016. 